\title{
JUSTIFICATION OF CYCLICAL EFFECTS ON THE RESERVOIRS WITH HIGH VISCOSITY OIL
}

\author{
• • отенев, • • ейгм н, • • ух метшин, • • оном рев, \\ • . улт нов, . . физов, . . еляев , . . отенев \\ Yu. A. Kotenev, Yu. V. Zeigman, V. Sh. Mukhametshin, A. I. Ponomarev,
} Sh. Kh. Sultanov, A. R. Khafizov, A. S. Belyaeva, A. Yu. Kotenev

фимский госуд рственный нефтяной технический университет, г. $\quad$ ф

лючевые слов : высоковязк я нефть; циклическое воздействие; тиксотропное свойство нефти Key words: heavy oil; cyclic effect; the thixotropic property of crude oil

собенностью н стоящего и предстоящего эт п р звития нефтег зовой отр сли является освоение месторождений высоковязких, тяжелых, сверхтяжелых нефтей с целью увеличения ресурсов углеводородного сырья и созд ние технологий их добычи. ерспективы $\mathrm{p}$ зр ботки месторождений с высоковязкой нефтью могут определяться методическим подходом, включ ющим: дет льное изучение геологического строения; изучение опыт эксплу т ции схожих месторождений; численную, л бор торную и эксперимент льную д пт цию р бочих гентов к конкретным геолого-технологическим условиям месторождения.

течественные 3 п сы высоковязкой и тяжелой нефти сост вляют $\approx 13 \%$ от общего объем р звед нных в оссии ресурсов нефти. о д нным нститут химии нефти ибирского отделения , сумм рные з п сы олго- р льского и п дноибирского нефтег зоносных 6 ссейнов сост вляют более $71 \%$ от общероссийских з п сов тяжелой нефти. олго- р льские виды высоковязкой нефти, по ср внению с

п дно- ибирскими, являются более сернистыми, п р финистыми, смолистыми, с большим содерж нием в н дия, но с меньшим количеством р створенного г 3 . территории республики т рст н выявлено более 450 месторождений и проявлений природных битумов и высоковязких месторождений. основном они р сположены 
Н 3 п дном и южно-восточном склон х жно- т рского свод . тносительно 6 л нс н ч льных 3 п сов в т рст не н долю 3 п сов высоковязкой нефти (более 30 м $\quad$ с) приходится около $43 \%$ [1]. сновн я доля з п сов высоковязкой нефти приходится н отложения нижнего и среднего к рбон [2]. сследов ниями в p бот x [1-6] уст новлены з кономерности изменения физико-химических свойств нефтей по р зрезу. о мере уменьшения глубины з лег ния продуктивных пл стов отмеч ются утяжеление р зг зиров нных нефтей, увеличение в них содерж ния серы, уменьшение г зового ф ктор и содерж ния легких углеводородов.

ксплу т ция продуктивных объектов с высокой вязкостью нефти имеет особенности, в условиях сложного геологического строения выбор технологии добычи нефти требует дет льной прор ботки. тепноозерское нефтяное месторождение, н ходящееся в республике т рст н, х р ктеризуется специфическим строением з лежей нижнего к рбон, широким р звитием в них эрозионных врезов к к площ дного, т к и руслового типов [6-8]. оэтому необходимо иметь в виду дв в жных момент . о-первых, в процессе эксплу т ции многих месторождений з п дного склон жно- т рского свод уст новлено гидродин мическое в3 имодействие $з$ лежей нефти турнейского и визейского ярусов $[2,9,10]$. оскольку эрозионные врезы, з полненные рыхлым песком или сл босцементиров нным песч ником, предст вляют собой не что иное, к к естественные к вернын копители нефти, имеющие зн чительные р змеры и потому дренирующие большой объем к рбон тных коллекторов, то, очевидно, приток нефти из к рбон тов должен быть тем зн чительнее, чем лучше коллекторские свойств терригенного пл ст и больше площ дь к верны $[6,8]$. о-вторых, н тепноозерском месторождении имеется зн чительн я многопл стовость в терригенной толще. ри этом естественные режимы р зр ботки бобриковских пл стов р зличны: если пл сты в эрозионных врез х возможно дост точно эффективно эксплу тиров ть н жестком природном режиме, то 3 лег ющий пл шевидный пл ст в в $_{1}$ зр 6 тыв ть без применения гидродин мических режимов не эффективно [8]. жно отметить и высокую вязкость нефти, достиг ющую до 620 м с [11-13]. юбое решение при $\mathrm{p}$ зр ботке подобных з лежей нужд ется в дет льном предв рительном исследов нии и обоснов нии. особую группу выделяются проблемы, связ нные с определением технологических эффектов от применения методов повышения нефтеотд чи и эксперимент льных исследов ний реологических и фильтр ционных х р ктеристик нефтей. е лизуемым способом р зр ботки месторождения в н стоящее время является орг низ ция эффективного поддерж ния пл стового д вления. истем тическое исследов ние и р зр ботк н учных основ технологии нест цион рного воздействия были з ложены в р бот х . . рб товой, . . ургучев [14]. ибольшее р спростр нение получил технология, по которой периодически прекр щ ется 3 к чк воды н уч стке при сохр нении средних темпов 3 к чки $з$ длительный период, то есть в течение первого полупериод проводится отключение н гнет тельных скв жин, з тем в течение второго полупериод проводится н гнет ние воды при повышенных р сход х. овместно с . . едоровым ( юм ) было обоснов но, р ссчит но и смоделиров но циклическое воздействие.

ффективное применение циклического воздействия возможно при слоистой неоднородности пл стов по вертик льному сечению и н личии дост точной вертик льной вз имосвязи в пл сте. ля н лиз эффективности применения циклического воздействия необходимо уточнение п р метров пл стов по р зрезу для к ждого н лизируемого горизонт . еолого-ст тистические р зрезы горизонтов приведены в т блице 1.

редв рительный н лиз этих д нных пок зыв ет, что условиям успешного применения циклического з воднения отвеч ет объект р зр ботки нижнего к рбон тепноозерского месторождения. 
еолого-ст тистические р зрезы нефтен сыщенных горизонтов

\begin{tabular}{|c|c|c|c|c|}
\hline л ст & $\begin{array}{c}\text { редневзвешенн я } \\
\text { нефтен сыщенн я } \\
\text { толщин , м }\end{array}$ & $\begin{array}{c}\text { ористость, } \\
\text { д.е. }\end{array}$ & $\begin{array}{c}\text { ефтен сыщенность, } \\
\text { д.е. }\end{array}$ & $\begin{array}{c}\text { рониц емость, } \\
\text { мкм }^{2}\end{array}$ \\
\hline шир-3 & 1,57 & 0,18 & 0,71 & 0,151 \\
\hline шир-1 & 1,9 & 0,22 & 0,60 & 0,151 \\
\hline ерей-5 & 0,91 & 0,131 & 0,73 & 0,089 \\
\hline ерей-4 & 1,13 & 0,145 & 0,754 & 0,157 \\
\hline ерей-3 & 2,10 & 0,151 & 0,761 & 0,274 \\
\hline ерей-2 & 1,47 & 0,147 & 0,732 & 0,253 \\
\hline ерей-1 & 0,80 & 0,143 & 0,745 & 0,235 \\
\hline шкир-2 & 2,31 & 0,14 & 0,75 & 0,345 \\
\hline шкир-1 & 5,18 & 0,14 & 0.75 & 0,320 \\
\hline обр-10 & 1,04 & 0,206 & 0.866 & 1,185 \\
\hline обр-01 & 4,71 & 0,239 & 0.938 & 1,878 \\
\hline обр-02 & 3,0 & 0,242 & 0.95 & 5,144 \\
\hline обр-03+04 & 4,7 & 0,271 & 0.948 & 0,053 \\
\hline урне & 3,73 & 0,154 & 0.702 & \\
\hline
\end{tabular}

етодик прогнозиров ния и результ ты р счетов процесс ицклического з воднения.

счет п р метров циклического воздействия производился с использов нием двухмерной по вертик льному сечению численной модели двухф зной фильтр ции в слоисто-неоднородном пл сте. редпол г лось, что пл ст р зр б тыв ется рядной системой скв жин, с р сстоянием между н гнет тельным и добыв ющим ряд ми, р вным 300 м. д ч реш л сь в двухмерном по вертик льному сечению в ри нте без учет к пиллярных и гр вит ционных сил. ертик льн я прониц емость пл ст , котор я определяет гидродин мическую связь пропл стков в нефтен сыщенном горизонте, сост влял 0,01 от зн чения горизонт льной сост вляющей. ериод циклического воздействия состоял из $\mathrm{p}$ вных полупериодов, соответствующих режиму ост новки только н гнет тельных скв жин. течение полупериод 3 к чки воды д вление н гнет ния повыш лось н $30 \%$, что обеспечив ет выполнение пл н 3 к чки. сходн я н сыщенность пл ст водой и нефтью определял сь из решения 3 д чи о 3 воднении до момент достижения текущей обводненности продукции н исследуемом пл сте $(70 \%)$. счеты проводились для нескольких десятков циклов воздействия до достижения обводненности продукции 97 \% [13, 15$]$.

ример результ тов р счетов темп добычи нефти при обычном 3 воднении и применении циклического воздействия предст влен н рисунке 1.

Период воздействия 30 суток

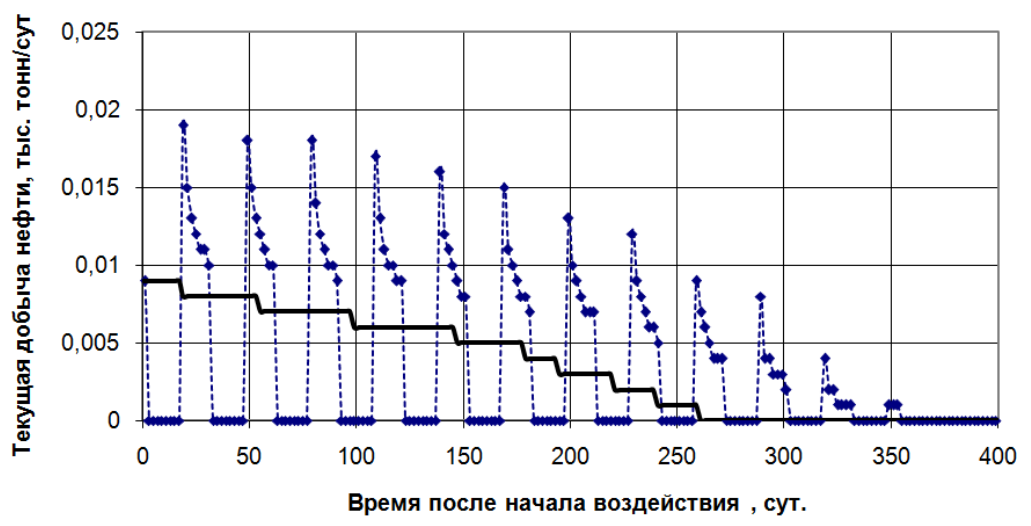

ис. 1. ример р счет темпов добычи нефти при з воднении (сплошн я крив я)

и циклическом воздействии (прерывист я крив я) н втором объекте 
копленн я добыч нефти при з воднении и циклическом воздействии р вн площ ди под соответствующими кривыми (см. рис. 1). зность н копленных объемов нефти при циклическом воздействии и 3 воднении сост вляет дополнительную добычу нефти от воздействия. т р зность для всего период p зр ботки приведен для р зличных периодов воздействия н рис. $2 . \quad$ ростом период дополнительн я добыч возр ст ет, достиг я м ксимум при величине период 10 сут, 3 тем п д ет до отриц тельных величин (см. рис. 2). ким обр зом, определен оптим льный период цикл и дополнительн я добыч нефти для н лизируемого объект -полигон . ксим льное зн чение дополнительной добычи нефти (10 $000 \mathrm{~T} / \quad)$ соответствует 3,5\% прирост коэффициент нефтеотд чи уч стк , н котором проводится воздействие [14-17].

Влияние полупериода циклического воздействия на дополнительую добычу нефти

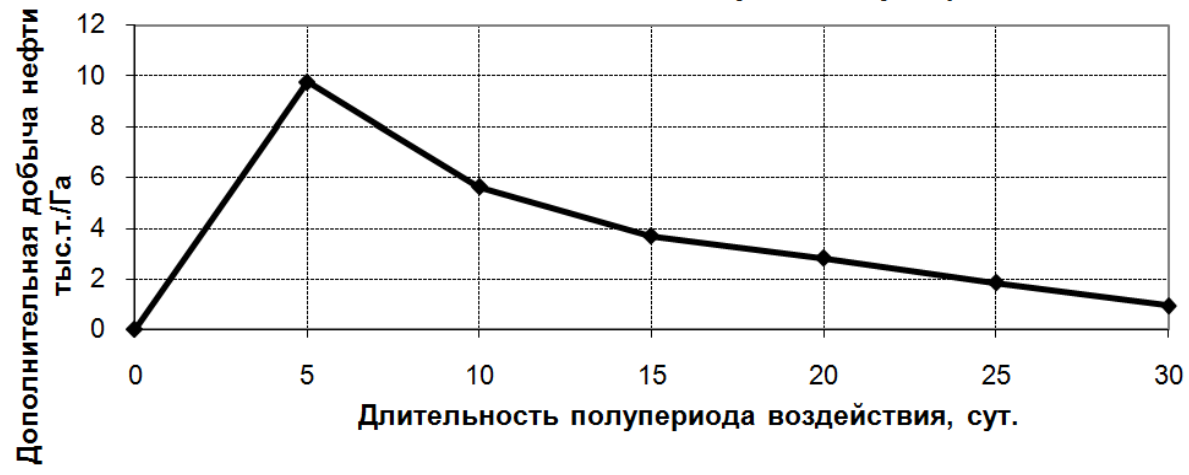

ис. 2. ополнительн ядобыч нефти при циклическом воздействии, приведенн як полному периодувоздействия. лощ дьр счетного уч стк сост вляет $1000 \mathrm{~m}^{2}$

ыполненные численные р счеты нужд ются в дополнительных исследов ниях реологических и фильтр ционных свойств пл стовой нефти. ля возможности ре лиз ции циклического воздействия в жным является исследов ние тиксотропных свойств нефти $[9,10,16]$. овместно с . . ог чевым (« орный университет») проведены эксперимент льные исследов ния реологических и фильтр ционных свойств проб нефтей, отобр нных из 14-ти скв жин, вскрывших продуктивные горизонты нижнего и среднего к рбон , в том числе 10-ти скв жин тепноозерского месторождения. сследов ния сводились к получению эксперимент льной з висимости между объемными р сход ми нефти через к пилляр или обр зец породы и переп д ми д вления н их конц х. пыты проводились в условиях «фиксиров нных объемных р сходов - меняющихся переп дов д вления». змерение переп дов д вления производилось при уст новившихся режим х течения нефти.

помощью реологических линий и кривых фильтр ции определялись основные реологические и фильтр ционные п р метры дег зиров нной и пл стовой нефти: предельное дин мическое н пряжение сдвиг ( ), н пряжение сдвиг предельного р зрушения структуры ( ), гр диент дин мического д вления сдвиг ( ), гр диент д вления сдвиг предельного р зрушения структуры ( ), эффективные вязкость и подвижность нефти с р зрушенной и нер зрушенной структурой, индексы ном лий вязкости и подвижности нефти ( ).

езульт ты этих исследов ний по одной из скв жин предст влены в т бл. 2 и 3 , т кже н рис. 3. 
езульт ты экспериментов по определению реологических свойств пл стовой нефти скв. 2252 тепноозерского месторождения

\begin{tabular}{|c|c|c|c|c|}
\hline \multirow{2}{*}{$\begin{array}{c}\text { корость } \\
\text { сдвиг } \\
\gamma 10^{2}, \mathrm{c}^{-1}\end{array}$} & \multicolumn{2}{|c|}{ пряжение сдвиг $\tau}$, & \multicolumn{2}{c|}{ ффективн я вязкость $\mu$, м } \\
\hline & рямой ход & бр тный ход & рямой ход & бр тный ход \\
\hline 1,12 & 0,018 & 0,010 & 1610 & 893 \\
\hline 1,46 & 0,021 & 0,012 & 1440 & 822 \\
\hline 2,94 & 0,028 & 0,017 & 952 & 378 \\
\hline 5,11 & 0,031 & 0,020 & 607 & 375 \\
\hline 11,2 & 0,042 & 0,042 & 375 & 370 \\
\hline 14,6 & 0,054 & 0,054 & 370 & 391 \\
\hline
\end{tabular}

езульт ты экспериментов по определению фильтр ционных свойств пл стовой нефти скв. 2252 тепноозерского месторождения (в обр зце породы с =0,003 мкм $\left.{ }^{2}\right)$

\begin{tabular}{|c|c|c|c|c|}
\hline \multirow{2}{*}{$\begin{array}{c}\text { корость } \\
\text { фильтр ции } \\
\mathrm{v} 10^{10}, \mathrm{M} / \mathrm{c}\end{array}$} & \multicolumn{2}{|c|}{ р диент д вления $\operatorname{grad}$ p, } & \multicolumn{2}{|c|}{$\begin{array}{c}\text { Ффективн я подвижность }(\kappa / \mu) 10^{5}, \\
\text { мКм }^{2} / \mathrm{M} \text { с }\end{array}$} \\
\hline & рямой ход & бр тный ход & рямой ход & бр тный ход \\
\hline 1,47 & 0,062 & - & 0,24 & - \\
\hline 1,92 & 0,066 & - & 0,29 & - \\
\hline 3,91 & 0,122 & - & 0,32 & - \\
\hline 6,78 & 0,212 & - & 0,32 & - \\
\hline 14,7 & 0,459 & - & 0,32 & - \\
\hline
\end{tabular}

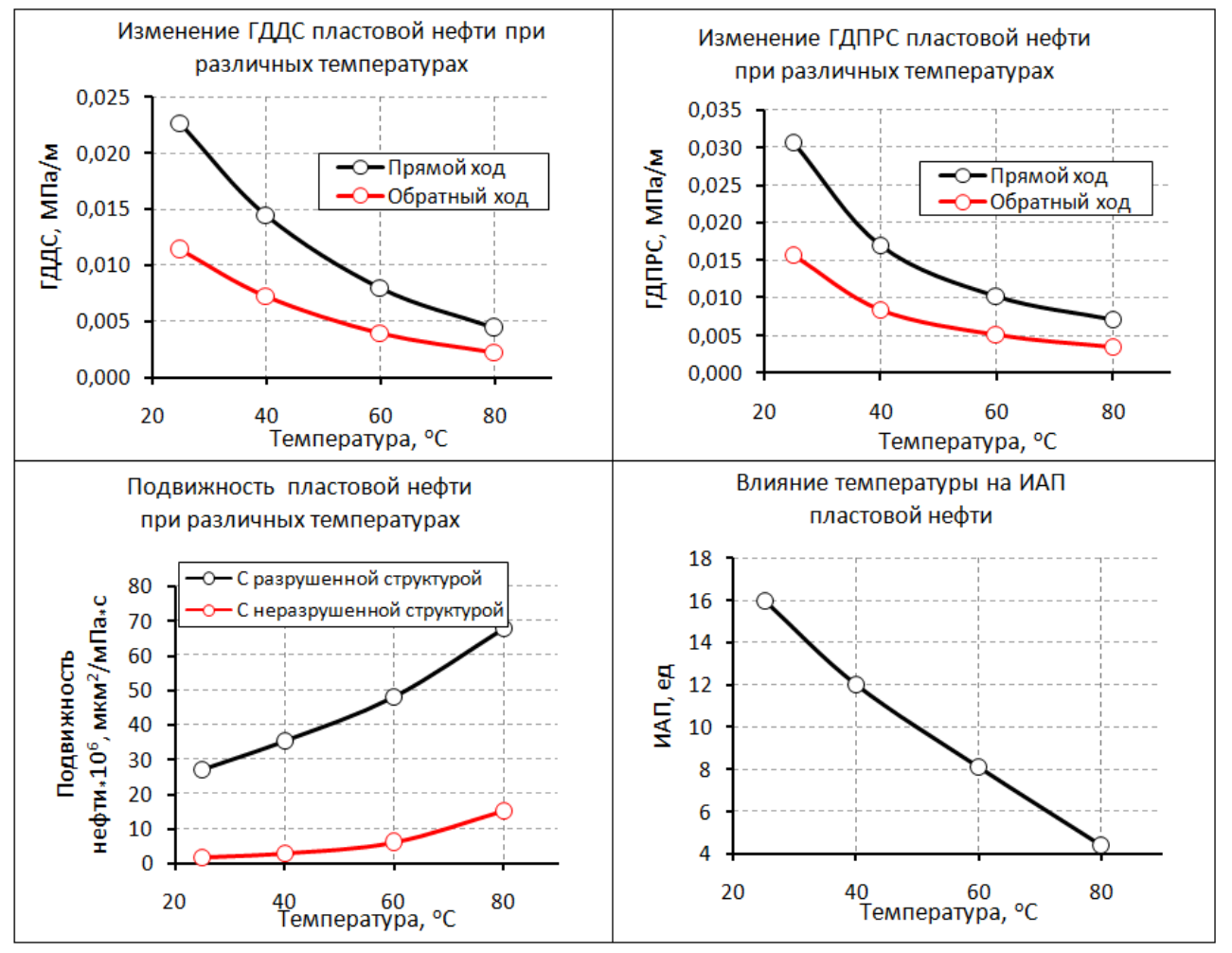

ис. 3. еологические линии и кривые фильтр ции пл стовой нефти скв. 2252 тепноозерского месторождения 
помощью полученных результ тов по к ждой скв жине определены реологические и фильтр ционные п р метры исследов нных пл стовых нефтей, предст вленные в т бл. 4.

ксперимент льные исследов ния реологических и фильтр ционных х р ктеристик нефти тепноозерского месторождения пок з ли, что их отличительными особенностями являются:

- высокие зн чения плотности и вязкости дег зиров нных нефтей, которые объясняются повышенным содерж нием в их сост ве сф льтосмолистых веществ;

- высокие зн чения вязкости пл стовых нефтей при низких зн чениях г зового ф ктор ;

- при низких зн чениях г зового ф ктор пл стовых нефтей отмечено высокое содерж ние в попутном г зе зот .

еологические и фильтр ционные п р метры дег зиров нных нефтей тепноозерского месторождения

\begin{tabular}{|c|c|c|c|c|c|c|c|c|c|c|}
\hline \multirow{2}{*}{ ок 3 тели } & \multicolumn{10}{|c|}{ ефть скв жины } \\
\hline & 2462 & 2172 & 2220 & 637 & 2233 & 2129 & 687 & 2245 & 2252 & 132 \\
\hline \multicolumn{11}{|c|}{ еологические п р метры } \\
\hline при прямом ходе, & 0,026 & 0,015 & 0,023 & 0,014 & 0,019 & 0,019 & 0,019 & 0,025 & 0,026 & 0,018 \\
\hline при обр тном ходе, & 0,014 & 0,008 & 0,012 & 0,007 & 0,010 & 0,010 & 0,010 & 0,013 & 0,013 & 0,010 \\
\hline при прямом ходе, & 0,036 & 0,021 & 0,031 & 0,019 & 0,026 & 0,026 & 0,026 & 0,034 & 0,035 & 0,025 \\
\hline при обр тном ходе, & 0,019 & 0,011 & 0,017 & 0,010 & 0,014 & 0,014 & 0,014 & 0,018 & 0,019 & 0,014 \\
\hline 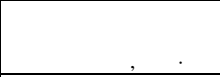 & 230 & 375 & 200 & 220 & 364 & 516 & 220 & 575 & 370 & 274 \\
\hline 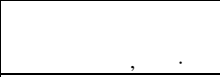 & 982 & 1250 & 890 & 893 & 1430 & 1700 & 982 & 1960 & 1610 & 1160 \\
\hline & 4,3 & 3,3 & 4,4 & 4,1 & 3,9 & 3,3 & 4,5 & 3,4 & 4,4 & 4,2 \\
\hline \multicolumn{11}{|c|}{ ильтр ционные п р метры } \\
\hline $\begin{array}{c}\text { рониц емость обр зЦ } \\
\text { породы, мкм }{ }^{2} \\
\end{array}$ & 0,010 & 0,010 & 0,010 & 0,010 & 0,003 & 0,010 & 0,003 & 0,010 & 0,003 & 0,010 \\
\hline $\begin{array}{c}\text { при прямом ходе, } \\
\text { /M }\end{array}$ & 0,025 & 0,014 & 0,021 & 0,013 & 0,036 & 0,018 & 0,037 & 0,023 & 0,049 & 0,017 \\
\hline $\begin{array}{c}\text { при обр тном ходе, } \\
/ \mathrm{M}\end{array}$ & 0,012 & - & 0,011 & 0,006 & - & - & - & - & - & - \\
\hline $\begin{array}{c}\text { при прямом ходе, } \\
/ \mathrm{M}\end{array}$ & 0,033 & 0,019 & 0,029 & 0,017 & 0,049 & 0,024 & 0,050 & 0,032 & 0,067 & 0,024 \\
\hline $\begin{array}{c}\text { при обр тном ходе, } \\
/ \mathrm{M}\end{array}$ & 0,017 & - & 0,015 & 0,009 & - & - & - & - & - & - \\
\hline $\begin{array}{c}\text { одвижность нефти } \\
\text { с р зрушенной } \\
\text { структурой, } \text { мкм²/M }^{\text {c }} \\
\end{array}$ & $2,17 \times 10^{-5}$ & $1,33 \times 10^{-5}$ & $2,51 \times 10^{-5}$ & $2,27 \times 10^{-5}$ & $0,33 \times 10^{-5}$ & $0,98 \times 10^{-5}$ & $0,54 \times 10^{-5}$ & $0,87 \times 10^{-5}$ & $0,32 \times 10^{-5}$ & $1,88 \times 10^{-5}$ \\
\hline $\begin{array}{c}\text { одвижность нефти } \\
\text { с нер зрушенной } \\
\text { структурой, мкм²/м c } \\
\end{array}$ & $0,67 \times 10^{-5}$ & $0,86 \times 10^{-5}$ & $0,74 \times 10^{-5}$ & $1,05 \times 10^{-5}$ & $0,30 \times 10^{-5}$ & $0,70 \times 10^{-5}$ & $0,33 \times 10^{-5}$ & $0,52 \times 10^{-5}$ & $0,24 \times 10^{-5}$ & $0,77 \times 10^{-5}$ \\
\hline & 3,2 & 1,5 & 3,4 & 2,2 & 1,1 & 1,4 & 1,6 & 1,7 & 1,3 & 2,4 \\
\hline
\end{tabular}

бр зцы исследов нных нефтей при темпер туре, р вной пл стовой, обл д ют ном лиями вязкости и подвижности, и их можно отнести к кл ссу неньютоновских нефтей. кое поведение нефтей объясняется н личием в них простр нственной структуры из сф льтеновых ч стиц.

ильтр ция исследов нных нефтей через обр зцы естественных горных пород происходит при высоких зн чениях гр ничных гр диентов д вления, низких и переменных зн чениях подвижности нефти, что, безусловно, будет отриц тельно ск зыв ться н процессе ее извлечения из пл ст и должно учитыв ться при про- 
ектиров нии р зр ботки з лежей этих нефтей. роме того, все исследов нные нефти обл д ют тиксотропными свойств ми, которые выр ж ются в увеличении гр ничных н пряжений сдвиг и гр диентов д вления при ост влении нефти в покое из3 упрочнения ее простр нственной структуры. ти свойств необходимо учитыв ть при проектиров нии циклических методов воздействия н продуктивный пл ст, т кже при пл ниров нии эксплу т ции скв жин н периодических режим х.

ким обр зом, приоритетным условием достоверного прогнозиров ния циклического воздействия для продуктивных пл стов с высоковязкой нефтью является совместное исследов ние и изучение реологических и фильтр ционных свойств высоковязких нефтей, в том числе определение тиксотропными свойств ми, т кже выполнение м тем тических р счетов по выбору режим з к чки р бочего гент . ля условий тепноозерского месторождения оптим льным полупериодом 3 к чки является 10 суток.

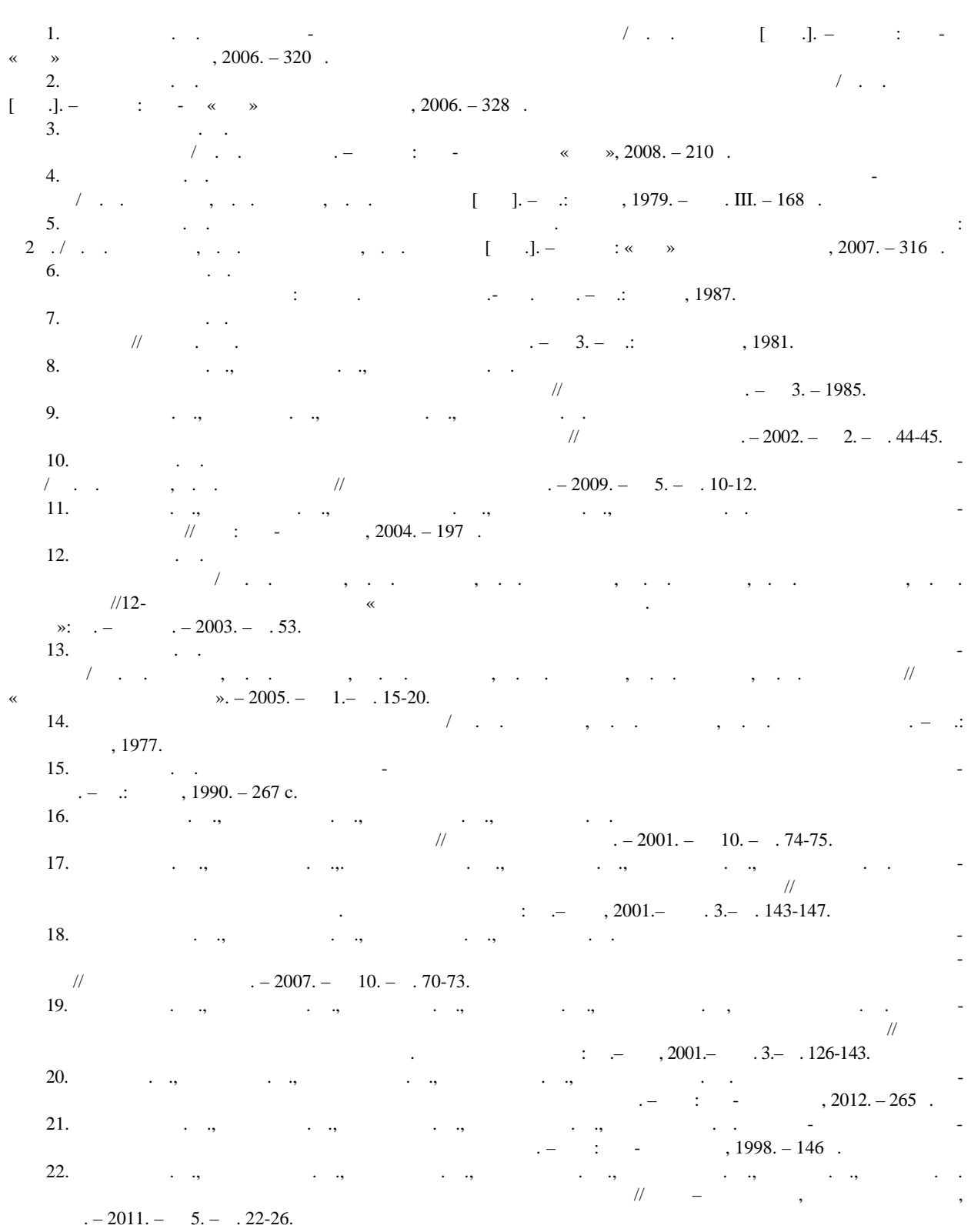

12. отенев собенности выр ботки з п сов высоковязких нефтей в условиях сложного геологического строения месторождения / . . отенев, . . киров, . . см гилов, . . улт нов, . . йнетдинов, .

йрединов //12-й вропейский симпозиум « овышение нефтеотд чи пл стов. своение трудноизвлек емых 3 п сов нефти»: тр. - 3 нь. $-2003 .-$. 53.

13. отенев . . ерспективы освоения трудноизвлек емых з п сов высоковязких нефтей в к рбон тных коллектор х / . . отенев, . . ндреев, . . улт нов, . . едоров, . . кляров, . . см гилов //

14. иклическое з воднение нефтяных пл стов / . . ургучев, . . ынков , . . . рб тов и др. - .. , 1977.

15. ок рев . омплексный геолого-промысловый контроль з текущей нефтеотд чей при вытеснении нефти водой. - $\quad .:$ едр, $1990 .-267$ с.

16. юняйкин . ., енер лов . ., ейгм н . ., ог чев . . овершенствов ние технологий глушения скв жин в условиях низкопрониц емых коллекторов // ефтяное хозяйство. - 2001. - № 10. - 74-75.

17. едоров . ., киров . ., йрединов . ., ндреев . ., отенев . ., улт нов . . рогнозиров ние и н лиз применения циклического воздействия н тепноозерском месторождении // етоды увеличения нефтеотд чи трудноизвлек емых з п сов. роблемы и решения: р.- ф , 2001.- ып. 3.- . 143-147.

18. уг йбеков . ., улт нов . ., рл мов . ., ибисов . . р внительный н лиз применения искусственных нейросетей и метод гл вных компонент при кл ссифик ции эксплу т ционных объектов и прогноз нефтедобычи // ефтяное хозяйство. - 2007. - № 10. - . 70-73.

19. едоров . ., киров . ., ндреев . ., отенев . ., улт нов . , йрединов . . еологом тем тическое моделиров ние применения методов увеличения нефтеотд чи н тепноозерском месторождении // етоды увеличения нефтеотд чи трудноизвлек емых з п сов. роблемы и решения: р.- , 2001.- ып. 3.- . 126-143.

20. узин . ., ндреев . ., убинский . ., улт нов . ., ух метшин . . еотехнологическое обоснов ние ресурсосберег ющих методов освоения трудноизвлек емых з п сов нефти. - ф : зд-во 2012. - 265 с.

21. улт нов . ., ндреев . ., отенев . ., г ф ров . ., ербинин . . еолого-промысловый н лиз эффективности применения методов увеличения нефтеотд чи. - ф : зд-во , $1998 .-146$ с.

22. ндреев . ., убинский . ., отенев . ., ияс ров . ., улт нов . ., узин . ., узин . ннов ционные технологии р зр ботки месторождений высоковязкой нефти // - нергетик , нергосбережение, кология. -2011 . - № 5. - . 22-26. 
ведения об втор $x$

отенев рий лексеевич, д. $m$. н. профессор, з ведующий к федрой геологии и р ведки нефтяных и г зовых месторождений, фимский госуд рственный нефтяной технический университет, тел. 8(347)2416192

ейгм н рий ени минович, д. П. н., профессор, $з$ ведующий к федрой $p$ зр ботки $и$ эксплу т иии нефтег зовых месторождений,

фимский госуд рственный нефтяной технический университет, г. $\phi, 8(347) 2420939$, e-mail: jvzeigman@ya.ru

ух метиин ячесл в рифуллович, д. г.-м. н., профессор к федры р зведки и р зр ботки нефтяных и г зовых месторождений директор, фили л фимского госуд рственного нефтяного технического университет в г. $\kappa$ тябрьском; тел. 8(34767)65590, e-mail vsh@of.ugntu.ru

оном рев лекс ндр осифович, д. профессор, 3 ведующий $\kappa$ федрой $p$ зр ботки $и$ эксплу $m$ ции г зовых и г зоконденс тных ме сторождений, фимский госуд рственный нефтяной технический университет, г. $\phi$, тел. 8(347)2431779, e-mail: kafedrargkm@mail.ru

\section{ултнов миль нифович, д. $m$. н.,} профессор к федры геологии и р зведки нефтяных и г зовых месторождений, фимский госу д рственный нефтяной технический универсиmет, 2. $\phi$, тел. 8(347)2416189, e-mail: ssultanov@mail.ru

физов йр т имович, д. т. н., профессор $\kappa$ федры $p$ зр ботки и эксплу т иии г зовых $и$ 2 зоконденс тных месторождений, фимский госуд рственный нефтяной технический универcumem, г. $\phi, 8(347) 2431779$

еляев льбин гитовн, д. т. н., 3 ведующий спир нтурой «еофизик», 2. $\phi$, еспублик шкортост $н$

отенев ртем рвевич, к. препод в тель к федры геологии $и$ р зведки нефтяных и г зовых месторождений, фимский госуд рственный нефтяной технический универcumem, г. ф , тел. 8(347)2416192
Information about the authors

Kotenev Yu. A., Doctor of Engineering, professor, head of the chair of geology and exploration of oil and gas fields, Ufa State Petroleum Technological University, Bashkortostan Republic, phone: 8(347)2416192

Zeigman Yu. V., Doctor of technical sciences, professor, Head of oil and gas fields development and exploitation chair; Ufa State Petroleum Technological University, Bashkortostan Republic, Russia; $e$ mail:jvzeigman@ya.ru

Mukhametshin V. Sh., Doctor of geology and mineralogy, professor of research and development of oil and gas fields chair; Ufa State Petroleum Technological University, Oktyabrsky city, Bashkortostan Republic,e-mail:vsh@of.ugntu.ru

Ponomarev A. I., Doctor of technical sciences, professor; Head of gas and gas condensate fields development and exploitation chair; Ufa State Petroleum Technological University; Bashkortostan Republic, phone: 8(347)2431779, e-mail: kafedrargkm@mail.ru

Sultanov Sh. Kh., Doctor of Engineering, professor of the chair of geology and exploration of oil and gas fields, Ufa State Petroleum Technological University, Ufa, Bashkortostan Republic, phone: 8(347)2416189,e-mail: ssultanov@mail.ru

Khafizov A. R., Doctor of technical sciences, professor of gas and gas condensate fields develop ment and exploitation chair; Ufa State Petroleum Technological University; Bashkortostan Republic phone: 8(347)2431779, e-mail: kafedrargkm@mail.ru

Belyaeva A. S. Doctor of Engineering, head of the graduate courses at OJSC NPF «Geophysica», Ufa, Bashkortostan Republic

Kotenev A. Yu., Doctor of Engineering, senior lecturer of the chair of geology and exploration of oil and gas fields, Ufa State Petroleum Technological University, Ufa, Bashkortostan Republic, phone: 8(347)2416192 